\title{
Margem de Segurança para Hiperviscosidade Plasmática para Prevenção de Trombose em Pacientes com Doença Cardiovascular após Vacinação contra COVID-19
}

\section{Safety Margin for Plasma Hyperviscosity in Cardiovascular Disease Patients after COVID-19 Vaccination for Thrombosis Prevention}

Rujittika Mungmunpuntipantip ${ }^{10}$ e Viroj Wiwanitkit ${ }^{1}$

Dr DY Patil, Universidade de Pune, ${ }^{1}$ Pune - Índia

\section{Caro Editor,}

Foi com grande interesse que lemos o artigo intitulado "Vacinação do Cardiopata contra COVID-19: As Razões da Prioridade". ${ }^{1}$ A Fvacinação contra a COVID-19 tem sido considerada a melhor maneira de se prevenir a doença, embora dados sobre sua segurança ainda sejam necessários. Um problema importante após a vacinação contra COVID-19 são as alterações reológicas que induzem a formação de coágulos intravasculares e complicações trombóticas. ${ }^{2}$ Mudanças na viscosidade sanguínea após a vacina da COVID-19 foram confirmadas. A vacina pode induzir uma rápida produção de anticorpo, o qual é uma proteína que pode aumentar a viscosidade do plasma em um valor estimado de 2,4 centipoise (cP) em relação a valores normais em uma pessoa saudável..$^{3,4} \mathrm{O}$ problema pode ocorrer se a viscosidade plasmática atingir níveis superiores a $5 \mathrm{cP}$, o que é considerado um estado de hiperviscosidade. ${ }^{5}$

Para qualquer pessoa que seja vacinada contra a COVID-19, deve existir uma margem de segurança para o problema de hiperviscosidade. Essa margem de segurança seria a diferença entre a viscosidade plasmática basal e o nível de hiperviscosidade. Uma preocupação em relação à margem de segurança para a hiperviscosidade deve ser considerada em relação a indivíduos com doença cardíaca subjacente. Observa-se que uma pessoa com dislipidemia ou doença cardiovascular apresenta uma viscosidade plasmática mais alta em comparação a uma pessoa saudável. ${ }^{6,7}$

Nesse artigo, ${ }^{1}$ os autores tentaram estimar uma margem de segurança para hiperviscosidade plasmática para indivíduos sadios e para aqueles com diferentes doenças cardíacas subjacentes que serão vacinados contra a COVID-19. Os valores estimados estão descritos na Tabela 1; as margens de segurança diferiram-se não somente entre indivíduos sadios e pacientes com doenças cardiovasculares, como entre diferentes doenças cardiovasculares. Uma pessoa com angina instável parece apresentar o maior risco. Pacientes com algumas doenças subjacentes podem apresentar valores mais baixos de margem de segurança, o que pode resultar em um risco maior de se desenvolver doença trombótica. Como recomendação, atenção especial deve ser dada a pacientes com doenças cardiovasculares com risco elevado de hiperviscosidade, e monitoramento de valores de viscosidade plasmática antes da vacinação pode ser útil.

Tabela 1 - Margem de segurança estimada para hiperviscosidade plasmática após vacinação contra COVID-19 em indivíduos sadios e pacientes com diferentes doenças cardiovasculares

\begin{tabular}{|c|c|c|}
\hline Grupos & Valor de viscosidade basal* (cP) & Margem de segurança estimada** (cP) \\
\hline Indivíduo sadio & 1,40 & 1,1 \\
\hline Paciente com dislipidemia & 1,44 & 1,06 \\
\hline Paciente com angina estável & 1,42 & 1,08 \\
\hline Paciente com angina instável & 1,66 & 0,84 \\
\hline Paciente com infarto do miocárdio & 1,53 & 0,97 \\
\hline
\end{tabular}

\section{Palavras-chave}

Viscosidade; Pacientes; Margem de Excisão.

Correspondência: Rujittika Mungmunpuntipantip •

Private Academic Consultant, Bangkok - Tailândia

Email:rujittika@gmail.com

DOI: https://doi.org/10.36660/abc.20210555 


\section{Carta ao Editor}

\section{Referências}

1. Martins WA, Oliveira GMM, Brandão AA, Mourilhe-Rocha R, Mesquita ET, Saraiva JFK, Bacal F, et al. Vaccinating Patients with Heart Disease Against COVID-19: The Reasons for Priority. Arq Bras Cardiol. 2021;116(2):213-8. doi: 10.36660/abc. 20210012 .

2. Merchant HA. COVID Vaccines and Thrombotic Events: EMA Issued Warning to Patients and Healthcare Professionals. J Pharm Policy Pract. 2021;14(1):32. doi: 10.1186/s40545-021-00315-w.

3. Joob B, Wiwanitkit V. Expected Viscosity After COVID-19 Vaccination, Hyperviscosity and Previous COVID-19. Clin Appl Thromb Hemost. 2021;27:10760296211020833. doi: 10.1177/10760296211020833.
4. Dalakas MC. High-Dose Intravenous Immunoglobulin and Serum Viscosity: Risk of Precipitating Thromboembolic Events. Neurology. 1994;44(2):223-6. doi: 10.1212/wnl.44.2.223.

5. Mehta J, Singhal S. Hyperviscosity Syndrome in Plasma Cell Dyscrasias. Semin Thromb Hemost. 2003;29(5):467-71. doi: 10.1055/s-2003-44554.

6. Irace C, Carallo C, Scavelli F, Esposito T, De Franceschi MS, Tripolino C, et al. Influence of Blood Lipids on Plasma and Blood Viscosity. Clin Hemorheol Microcirc. 2014;57(3):267-74. doi: 10.3233/CH-131705.

7. Fuchs J, Weinberger I, Rotenberg Z, Erdberg A, Davidson E, Joshua H, et al. Plasma Viscosity in Ischemic Heart Disease. Am Heart J. 1984;108(3):435-9. doi: 10.1016/0002-8703(84)90405-8. 